\title{
Türkiye'de İlk Modern Yerel Yönetim Denemesi Olan Altıncı Daire-İ Belediye İle Sixième Arrondissement Karşılaştırması
}

\author{
DOI: $10.26466 /$ opus.561163 \\ * \\ Abdullah Aydın \\ * Dr. Öğr. Üyesi Hatay Mustafa Kemal Üniversitesi İ̈BF, Uluslararası İlişkiler Bölümü \\ Antakya/Hatay \\ E-Posta: aaydin@mku.edu.tr \\ ORCID:0000-0002-1785-4999
}

Öz

Sanayi devrimi sonrası süreçle değişen sosyal kültürel yapı devletlerin yeni kurumlar oluşturmasını mecbur kılmıştır. Köyden kente gerçekleşen hızlı göç neticesinde köy-kent arasındaki nüfus dengesi çok ciddi oranda bozulmuş ve kentler yaşanılmayacak hale gelmeye başlamıştır. Kentleri yaşanılmaz kılan en büyük etkenlerin başında kentsel hizmetlerin kimler tarafından yapılacağı noktasındaki hizmet kargaşası yatmaktaydı. Bu soruna uzun dönem geçici çözümler bulmaya çalışan Batı bunun geçici çözümlerle hizmet üretmenin yetersiz olduğuna karar verip yerel yönetim kurma yolunu tercih etmiştir. Süreç olarak benzer olmasa da tarihsel olarak yerel yönetimlerin gelişimi Türkiye'de benzer bir süreç izlemiştir. Diğer bir anlatımla Batı'daki gelişimler özellikle de Fransa'daki yasal düzenlemeler takip edilerek bir Osmanl yerel yönetim modeli oluşturulmaya çalışılmıştır. Bunun en büyük göstergelerinden biri de altıncı daire-i belediyedir. İstanbul'un Beyoğlu ve Galata semtleri en gelişmiş bölgelerini kapsayan alanda kurulan Altıncı Bölge'nin adı, Tanzimat döneminde etkili olan Osmanlı bürokratlarının bir süre yaşadıkları Paris'in en seçkin ve modem kesiminin yaşadı̆̆̆, Sixieme Arrondissment'ten (Altıncı Bölge) esinlenmiştir. Bu çalışmada Fransız yerel yönetim düzenlemelerinin Osmanlı yansımalar üzerinde durularak, Beyoğlu ve Galata bölgelerinde kurulan altıncı daire-i belediye ile Paris'teki Sixieme Arrondissment arasındaki benzerlikler ortaya konulmaya çalışılacaktır.

Anahtar Kelimeler: $\quad$ Türk Yerel Yönetim Modernleşmesi, Fransız Yerel Yönetimleri, Altıncı Daire-İ Belediye, Sixieme Arrondissment 


\title{
Comparison of The Sixième Arrondisse and Sixth Region in Turkey Which is First Modern Experience of Local Government in Turkey
}

\begin{abstract}
As a result of the post-industrial revolution period, the changing social cultural structure obliged states to create new institutions. As a result of the rapid migration from the village to the city, the population balance between the village and the city has deteriorated considerably and the cities have started to become uninhabitable. One of the biggest factors that made the cities uninhabitable was the chaos of service at the point of who would do the urban services. The West, who has tried to find long-term workarounds to this problem, decided that it was insufficient to produce services with workarounds and decided to establish a local government. The process is similar but not as a historical development of local governments has followed a similar process in Turkey. In other words, the developments in the West and in particular the legal regulations in France have been followed to form an Ottoman local government model. One of the biggest indicators of this is the Sixth Region (altinci daire-i belediye). The name of the Sixth Region, established in the most developed regions of Istanbul, is inspired by Sixieme Arrondissment (Sixth Region), where the most distinguished and modern sections of Paris, where Ottoman bureaucrats lived for a while, lived during the Tanzimat period. In this study, it will be tried to reveal the similarities between the Altıncı Daire established in Beyoğlu and Galata regions and the Sixieme Arrondissment in Paris by focusing on the Ottoman reflections of French local government regulations.
\end{abstract}

Keywords: Turkish Local Government Modernization, French Local Governments, Sixth Region, Sixieme Arrondissment 


\section{Giriş}

Yerel yönetimlere olan ihtiyacın kentlerin kalabalıklaşması neticesinde ortaya çıkması, Batı dünyası için bir mecburiyeti ifade etmektedir. Köyden kente gerçekleşen hızlı göç neticesinde köy-kent arasındaki nüfus dengesi çok ciddi oranda bozulmuş ve kentler yaşanılmayacak hale gelmeye başlamıştır. Kentleri yaşanılmaz kılan en büyük etkenlerin başında kentsel hizmetlerin kimler tarafından yapılacağı noktasındaki hizmet kargaşası yatmaktaydı. Bu soruna uzun dönem geçici çözümler bulmaya çalışan Batı bunun geçici çözümlerle hizmet üretmenin yetersiz olduğuna karar verip yerel yönetim kurma yolunu tercih etmiştir. Bunu sadece süreçle alakalı bir tercih olmadığı aynı zamanda Burjuva- Aristokrat çekişmesinin burjuva lehine gelişme olduğu da aşikârdır. Zira Aristokrasi burjuvanın yerel hizmetler ile ilgili taleplerinin görmezden gelinmesi gerektiğini veya geçiştirilmesi gerektiğini savunmaktaydı. Burjuvazi ise kentsel hizmetlerin bireylere ve işletmelere en azından minimum seviyede de olsa devlet tarafından sağlanması gerekliliği üzerinde durmaktaydı. Son tahlilde Burjuvazi kazanmış ve yerel yönetimler modern manada kurumsallaşmaya başlamıştır.

Süreç olarak benzer olmasa da tarihsel olarak yerel yönetimlerin gelişimi Türkiye'de neredeyse paralel bir süreç izlemiştir. Daha açık bir ifadeyle Batı' daki gelişimler özellikle de Fransa' daki düzenlemeler takip edilerek bir Osmanlı yerel yönetim modeli oluşturulmaya çalışılmıştır. Bunun en büyük göstergelerinden biri de altıncı daire-i belediyedir. Beyoğlu ve Galata bölgelerini kapsayan alanda kurulan Altıncı Bölge'nin adı, Tanzimat döneminde etkili olan tanınmış Osmanlı bürokratlarının eğitim maksatlı gönderildikleri ve bir süre yaşadığı Paris'in en seçkin ve modem kesiminin yaşadığı, Sixieme Arrondissment' ten (Altıncı Bölge) esinlenmiştir (Eryılmaz 2005, s.393).

Bu çalışmada Fransız yerel yönetim düzenlemelerinin Osmanlı yans1maları üzerinde durularak, Beyoğlu ve Galata bölgelerinde kurulan altıncı daire-i belediye ile Paris'teki Sixieme Arrondissment arasındaki benzerlikler ortaya konulmaya çalışılmıştır. Bunu yaparken Türk ve Fransız yerel yönetimlerinde bahsedilmiştir. Ancak bu anlatım ayrıntılı ve kronolojik bir anlatım ile biçiminde olmamıştır. Zira bahsi geçen konu literatürde 
çokça değinilen ana konuların başında gelmektedir. Bunun yerine çalışmanın ana perspektifini oluşturan altıncı daire-i belediye ile Paris'teki Sixieme Arrondissment ile alakalı önemli bir takım kırılma noktalarından bahsedilip neden Fransa'daki bir bölgenin, ne şekilde Türkiye yerel yönetim geleneğine örnek oluşturduğu üzerinde durulmuştur.

\section{Türk Yerel Yönetim Modernleşmesi}

Türk yerel yönetim modernleşmesi sürecini demokratik çerçevede ele alındığında Tanzimat'la başlatıp 1963 yılındaki ilk tam manasıyla demokratik yerel seçimlere kadar getirmek gerekmektedir. Zira yerel yönetimlerin modern manada bir ihtiyaç olarak belirdiği andan itibaren temel hareket noktalarından biri de demokratikleşmedir. Nitekim her ne kadar ilk denemelerde demokratik seçimlere pek rastlanmasa da sivilleşme yönündeki adımlar bile olumlu karışlanmıştır (Belli, 2019, s.89-90). Her ne kadar inişli çıkışlı bir trend izlese de demokratik yerel yönetime doğru geçiş süreci her adımda yeni bir boyuta geçmiştir.

Türk devlet geleneği incelendiğinde adem-i merkeziyetçi bazı unsurları Türkiye merkezli ilk Türk devletinden itibaren bünyesinde barındırdığı aşikardır (Taş ve Çiçek, 2017, s.307). Nitekim Anadolu Selçuklu Devletinde vilayetlerin örgütlenmesine bakıldığında yerinden yönetimin esasına göre teşkilatlandırılmış olduğu görülmektedir. Aynı zamanda bu vilayetlerin bir kısmı tamamen özerk olarak yönetilmektedirler. Ancak bu özerklik devletin zayıflama döneminde parçalanmayı hızlandıran ana etkenlerin başında gelmiştir. Bu çerçevede özerklik tanınan bölgeler daha sonra Anadolu beyliklerini şekillendiren bir unsur olarak görünmektedir. Bu çerçevede değerlendirildiğinde Osmanlı döneminde yerel yönetim anlayışından uzak durulma ${ }^{1}$ ve merkezin tahakkümün sağlanmaya çalışılması bir mecburiyet olarak algılanmıştır (Çiçek, 2014, s.54-55). Dolayısıyla bir takım bilim insanları Osmanlı Devleti'nde yerel yönetimlerin resmi statü kazanmasının ancak merkeziyetçilik sisteminin yerleşmesi ve yaygınlaşması gereği ve özellikle azınlıkların siyasal hayata katılması ve etnik

\footnotetext{
${ }^{1}$ Günümüz manası ile tam bir ve çok güçlü bir merkeziyetçilik dönemin şartları çerçevesinde mümkün değildir. Zira günümüzde merkez yerele anlık bir şekilde ulaşabilmektedir. Bu bağlamda günümüzde demokrasinin olmazsa olmazı olan yerel yönetimlerin özerkliği daha önemli hale gelmektedir. Teknolojik gelişmeler arttıkça merkezi otoritenin güç kullanma alanı, hızı ve kabiliyeti artmaktadır.
} 
haklar alanında özgürlük kazanmaları bağlamında dış devletlerin yaptığı baskılar neticesinde ortaya çıktığını belirtmektedirler (Keleş, 2012, s.157). Modern manada Türk yerel yönetimlerin ortaya çıkma sürecine kadar Osmanlı Devleti'nde yerel yönetimler tarafından yürütülen hizmetlerin ihtiyaçlar doğrultusunda klasik kurumlar² tarafından yürütülmesi söz konusudur (Tekeli, 1985, s.883; Keleş, 2010, s.19; Tan ve Belli, 2013, s.279-281). Hatta yerel hizmetlerin yerine getirilmesi açısından vakıf kurumlari ${ }^{3}$ ve kadı makamının işlevselliğini ve etkinliğini arttırma yönünde çalışmalar yapılmıştır (Pamuk, 1993, s.61). Bu çerçevede vakıfların üzerindeki merkezi denetim arttırılmış ancak bir türlü neticeler alınamamıştır (Ortaylı, 1985, s.185; Bayram, 2017, s.232). Diğer bir anlatımla yerel halkın yerel hizmetlerin yerine getirilmesinde sorumluluğu olan kişi ve kurumlarla ilgili bir tasarrufu bulunmamaktaydı. Yerel hizmetleri gerçekleştirecek kişiler merkez tarafından belirlenmekte yerel nitelikli olma ihtimali olan vakıflar ise merkez tarafında ciddi denetimlere tabi tutulmaktaydı (Şengül, 2012, s.25; Ökmen ve Yılmaz, 2009, s.98). Bu merkezileşmenin bir göstergesi de 1836 yılında kurulan Evkaf Nazırlığı' dır'.

Osmanlı Devleti'nde ilk modern belediye yönetiminin kurulması Kırım Savaşı'ndaki müttefiklerin etkisiyle söz konusu olmuştur. Zira o dönemde İstanbul genelinde yüz binden fazla yabancı uyruklu kişi yaşamakta olduğu görülmektedir. Dolayısıyla Avrupalı Devletler, bu kişilerin modern, bakımlı, temiz bir kentte yaşamalarını talep etmekteydiler (Türe, 2000, s.38; Koçak ve Ekşi, 2010, s.296). Bu bağlamda Tanzimat'ın akabinde ve Batı ile olan münasebetlerin artması neticesinde, Fransız komün idaresinden esinlenerek 1855 'te İstanbul'da ilk belediye yönetimi denemesi yapilmıştır (Ünal, 2011, s.243-244).

\footnotetext{
${ }^{2}$ Bunlar muhtesip, vali, kadı, vakıf ve loncalar şeklinde sıralanabilir (Ünal, 2011, s.243).

${ }^{3}$ Vakıf geleneğinin zirve yaptığı devlet Osmanlı'dır. Nitekim vakıf medeniyeti bir manada sloganlaşmış bir tabire dönüşmüştür. Ancak ilk örnekleri Bizans Devleti'ndeki yardım topluluklar/fonlarında da görülmektedir.

${ }^{4}$ Vakıflardan sorumlu bakanlıktır. Bakanlığın kurulması ile kadılık makamının sadece yargıda görevi kalmıştır (islamansiklopedisi, 2019).
} 


\section{Altıncı Daire-i Belediye ve Temel Özellikleri}

Kırım Savaşı ve sonrasında yaşanan süreç, Osmanlı Devleti'nin Batıyla olan münasebetlerini olumlu manada pekiştiren bir olay olarak değerlendirilmektedir. Zira süreçle beraber yaşanan gelişmeler birçok açıdan Osmanlı Devleti'ne etki etmiştir. Bu çerçevede İstanbul 1820'lerde gerek ticari münasebetlerdeki artış, gerekse Kırım Savaşı sebebiyle Galata'nın bir ara liman görevi taşıması Avrupalıların Galata ve Beyoğlu'nda iş alanlarında yer almalarına ve gün geçtikçe yerleşmelerine olanak ve ortam sağlamıştır. Daha önceleri Batılı diplomatik misyonların mesken tuttukları Beyoğlu ve civarı bu sürece müteakip Avrupalı tüccar, serbest meslek sahipleri ve Avrupai yaşam tarzını benimsemiş Levanten ${ }^{5}$ ve Müslüman/gayrımüslim Osmanlı tebaasının uğrak yeri haline gelmiştir. Nitekim Galata ve çevresindeki servet birikimi bir tür Osmanlı burjuvazisinin oluşmasının da önünü açan bir durum ortaya çıkartmıştır (Toprak, 1993, s.220-221).

Bu çerçevede bölge için bir takım talepler gelişmiş ve belli hizmetlerin alınması yönünde istekler saraya kadar gitmiştir. Yanı sıra Batı dünyasının da baskısı ile modern tarzda yerel yönetim anlayışının ilk uygulamasına 1857 yılında Beyoğlu'nda başlanmıştır (Bozkurt, 2007, s.3-5; Seyitdanlıŏlu, 1995, s.91-102; Ergin, 1934, s.109,110). Aslında 1857 yılında çıkartılan nizamname İstanbul sur içini 14 bölgeye ayırmayı öngören bir kapsama sahiptir. Ancak bir pilot uygulama olması bağlamında sadece Beyoğlu ve Galata'da kurulacak olan Altıncı Daire'den ${ }^{6}$ bahsetmekteydi.

Altıncı Daire kurulunca başına Mehmet Kamil Bey getirilmiştir (Kazgan, 2014, s.283). Kendisi Başhariciye teşrifatçısı olması hasebiyle yabancllarla ve diplomatik misyonlarla yakın ilişki içerisinde olan bir karakterdir (mimdap, 2019; Özdemir, 2011, s.89-90). Aynı zamanda farklı devlet işlerini de üstlenmesi belediye hizmetlerine gösterilen ehemmiyeti ortaya koyması açısından önem arz etmektedir.

\footnotetext{
${ }^{5}$ Levanten, özellikle Tanzimat sonrası süreçte İstanbul, İzmir ve Selanik gibi önemli ve büyük Osmanlı liman kentlerinde yoğunlaşan ve ticaretle hemhal olan, genel itibariyle Fransız, Italyan ve ingiliz kökenli Hristiyanlara verilen genel addır (tdk, 2019)

${ }^{6}$ Altıncı Daire sınırları Kasımpaşa deresinin sol kısmına düşen taraftan, Tatevle, Feriköy, dâhil olacak şekilde Küçük Çiftlik deresiyle, Dolmabahçe iskelesine ve sahil yoluyla Azab kapısından, Galata, Tophane, Salı Pazarı, Kabataş ve Dolmabahçe'ye kadar olan mahalleri kapsayacak şekilde belirlenmiştir (Bozkurt, 2007, s.4)
} 
Mehmet Kamil Bey sokakların temizliği, düzeni, lağım ve suyollarının tamir bakım ve inşası gibi bir takım hizmetlerin yerine getirilmesi kararı uygulamaya koymuştur. Akabinde Beyoğlu ve Galata'nın kadastro haritalarının oluşturulması için girişimde bulunmuştur. Taksim ve Tepebaşı'ndaki belli alanlara günümüzdeki park hüviyetini taşıyan umumi bahçeler inşa edilmiştir. Bir hastane kurmak için girişimlerde bulunmuş ve caddelerin gazyağı kullanarak ışıtan fenerlerle aydınlatılması sağlanmıştır. Bu çerçevede ilk olarak Cadde-i Kebir'de yani İstiklal Caddesinde gece aydınlatması uygulanmıştır (Beyoğlu, 2019).

$\mathrm{Bu}$ ve benzeri birçok iş yapılsa da belediye hizmetleri asla istenilen seviyeye ulaşamamıştır. Zira kaynak kıtlığı ülkenin içinde bulunduğu durum ve savaş ortamlarının çokça yaşanması yerel hizmetlerin kurumsallaşmasının önüne geçmiştir. Cumhuriyet dönemine bakılacak olursa Beyoğlu Belediyesi'nin 20 Nisan 1924'te kurulduğu görülmektedir. Beyoğlu, Cumhuriyetin ilk dönemlerinde Şişli, Beşiktaş ve Kemerburgaz'ı da içine alan bir durumdayken, 1930'da Beşiktaş ayrılmıştır. Akabinde 1936 y1lında ise Kemerburgaz Eyüp'e bağlanmıştır. 1954 yılında ise Şişli ilçesinin ayrı bir ilçe olarak kurulmasıyla bugünkü haline yakın bir hal almıştır. 1984 yılına değin İstanbul Belediyesi'ne bağlı bir şube olarak yönetilen Beyoğlu, 1984 yılında çıkartılan Büyükşehir ve İlçe Belediyelerini kapsayan kanun ile günümüz mevcut haline tam olarak dönüşmüştür. Belediye Binası ise Şişhane Meydanı'nda, Yolcuzade İskender, Meşrutiyet ve İlk Belediye Caddelerinin kesişme noktasında bulunmaktadır. Bina Edouard Blacque Bey'in ${ }^{7}$ ilk reisliği döneminde (1879-1883) inşa edilmiştir (Aktepe, 1982, s.270) Mimarı İstanbul'a ve özellikle Beyoğlu bölgesine birçok farklı eserler de kazandırdığı bilinen İtalyan Mimar Barborini'dir (tas-istanbul, 2019). Bu bina, ilk belediye binası olmasının yanında konumu ve estetiği

\footnotetext{
${ }^{7}$ Edouard Blaeque veya daha çok bilinen adıyla Blak Bey 1824 yılında doğmuştur. Babası olan Alexandre Blaeque Bey yani Aleksandr Blak 1826'da Izmir'e yerleşmiştir. Daha sonra Aleksandr Blak Osmanlı Devleti'nin resmi gazetesinin Fransızca nüshasını çıkartmakla görevlendirilmiştir. Babası Aleksandr Blak beyin vefatından sonra Blak Bey okuması için devlet tarafından Paris'e gönderilmiştir. Dönüşünde Babıali Tercüme Odası'na çalışmaya başlamıştır. Akabinde Blak Bey, 1867 tarihinde Amerika Birleşik Devletleri'ne Osmanlı Devleti'nin ilk ABD büyükelçisi olarak görevlendirilmiştir. 5 sene bu görevi yürüten Blak Bey Istanbul'a geri dönerek Matbuat Dairesi Müdürlüğü görevini üstlenmiştir. 1876 yılında Şura-yı Devlet üyesi olmuştur. Bir dönem ilk belediye tecrübesi olan Altıncı Daire'nin başkanlığını ve Adalar kaymakamlığını yürüttü. 1892 yılında vefat etmiştir (Aktepe, 1982, s. 270-277).
} 
nedeniyle bulunduğu muhite de adını vermiştir Yapıldığı tarihten itibaren belli dönemlerde kaymakamlık olarak kullanılmış olsa da halen Beyoğlu Belediyesi'nin merkez binası olma hüviyetini devam ettirmektedir (Beyoğlu, 2019).

\section{Fransız Yerel Yönetim Sistemine Genel Bakış}

Fransa, tarihsel olarak güçlü bir merkezileşme ve bazı prestijli üst düzey memurlar tarafından temsil edilen voluntarist (gönüllü) bir devlet yönetimi ile tanımlanmıştır. Bu bağlamda, yerel olarak, politikacıların kendi kamu politikalarını üretme veya uygulama konusunda gerçek bir gücü yoktur. 1980'li yıllarda, önemli kurumsal reformlar ve ideolojik değişiklikler bu istatistikçi modeli sorguladı ve merkezi yönetim ile yerel makamlar arasında yeni bir güç dengesi kurulmuş oldu. Bununla birlikte, merkezi yönetim Fransız siyasal yönetim sisteminde her zaman önemli bir aktördür (Reigner, 1999, s.1). Yerel politikacılar ve merkezi yönetim arasındaki mevcut ilişkiler saha hizmetlerinin yerine getirilmesi bağlamında, bölgeye göre çeşitlilik arz etmektedir. Dolayısıyla Fransa'daki yerel yönetim sistemi tam bir istikrar kazanmamasına rağmen, bir ortak yönetim modeli ortaya çalışması açısından pozitif yönlü gelişmeler yaşamaktadır (Ladrech, 1994, s.71). Bu gelişmeleri hızlandıran bir diğer etken de Avrupa Birliğinin yerel yönetimler açısından ortaya koymuş olduğu ilkelerdir. Ancak bu ilklerle ilgili merkezi yönetimin esas olduğu bir takım ülkelerin ve tabii ki Fransa'nın temel çekincesi merkezi yönetimin baypass edilerek yerel yönetimlerin muhatap alınması yönünde dügüümlenmektedir (Karayiğit, 2016, s.11).

Genel olarak bakıldığında yerel yönetimler, Fransız siyasal ve yönetsel hayatında ciddi ve önemli bir tarihsel geçmişi bulunmaktadır. 1789 Fransız İhtilalinden yaklaşık yüzyıl kadar sonra yerel yönetim sistemi bugünkü hüviyetini kazanmıştır. Fransız İhtilalinin akabinde yerel yönetim düzeni ile alakalı yapılan değişikliklerden en önemlilerinden bir tanesi Eski Rejim'in (Ancien Régim) küçük yerleşim yerlerinin (parois) belediyeye dönüştürülmesi şeklinde gerçekleştirilmiştir. 14 Aralık 1789 tarihinde çıartılan yasayla yerel topluluklara belli bir ölçek kıstasına bakılmaksızın belediye olma imkânı verilmiştir (Şengül, 2012, s.33). 
Vurgulandığı gibi, Fransa'nın devrimci Anayasası'nın 12 Aralık 1789 'da kabul ettiği, ikili görev modelini ortaya koymakta ve ayrıntılı bir şekilde açıklamaktadır. İkili görev modelinde klasik manada iki başlı yönetim bulunmakta ilk ayağını meclis ikinci ayağını ise başkan oluşturmaktadır. Meclis seçimlerle iş başına gelmekte ancak 1831 düzenlemesi ile belediye başkanı kral tarafından atanmaktadır. Yani yapı olarak bireyselleştirilmiş ve monokratik bir belediye başkanını (maire) ortaya koyan yerel yönetim sistemi vardır (Wollmann, 2008, s.286).

Fransa'da yerel yönetim sistemi anayasal bir statüye ancak Dördüncü Cumhuriyet Anayasası'yla kavuşabilmiştir. 1946 yılında yürürlüğe giren Anayasa'da, yerel yönetimlerden etraflıca bahsedilmiştir. Bu çerçevede yerel yönetimlerin ne şekilde yönetileceği ortaya konmuştur. Konulan ilkler bağlamında yerel yönetimlerin seçimle iş başına gelen meclisler arac1lığ 1 ile yönetileceği ve benzeri bazı ilkelere yer verilmiş ancak ortaya konan bu düzenlemeler Anayasa'nın yürürlükte bulunduğu dönem zarfında uygulamaya sokulamamıştır (Canatan, 2001, s.7).

Akabinde ortaya çıan ve Beşinci Cumhuriyeti kuran 4 Ekim 1958 tarihli Anayasada da yerel yönetimler ayrıntılı bir şekilde yer bulmuştur. Anayasanın 72. Maddesinde "Cumhuriyeti oluşturan yerel topluluklar belediyeler, iller ve denizaşırı ülkeler" ifadesi kullanılarak yerel yönetime verilen önem vurgulanmış ve ana kurucu unsurlardan biri olduğu üzerinde durulmuştur. Bu çerçevede yerel toplulukların mevcudiyeti Anayasal güvence kazanmıştır. Bu sayede herhangi bir yöntemle ortadan kaldırılmasının önüne geçilmiştir. Aynı maddenin devamında, yeni bir yerel yönetimlerin ancak yasa ile kurulabileceği hususu da açıklığa kavuşturulmuştur (Kayıkçı, 2003, s.27).

Günümüzde Fransa' da 'région (bölge)', 'département (il) ve 'commune (belediye)' üç tür yerel yönetim vardır ${ }^{8}$ (Gözler, 2019, s.2). 2018 yılı itibariyle Fransa' da 36,357 belediye, 101 il ve 18 bölge yerel yönetimi bulunması durumu söz konusudur (les Collectivités Locales en Chiffres 2018).

\footnotetext{
${ }^{8}$ Bazı kaynaklarda dört olarak geçmektedir. Dördüncü yerel yönetim birimi olarak ise kamu işbirliği kuruluşları sayılmaktadır (bknz. Yerel Yönetim Sistemleri Türkiye ve Fransa, Ispanya, Italya, Polonya, Çek Cumhuriyeti). Ancak kaynakların kahir ekseriyeti üç olarak ifade ettiği için çalışmada bu tasnif tercih edilmiştir.
} 
Fransa'da belediye sayısının bu denli fazla olmasında herhangi bir sınırlama olmaksızın tüm yerleşim yerlerine belediye statüsü verilmesinin etkisi vardır (Erbay,1999, s.59).

Fransa'nın 101 ili toplamda 343 ilçeye ayrılmıştır. İşte bu ilçe ifadesi "Arrondissement" olarak anılmaktadır. Arrondissement kelimesi incelendiğinde ilçe manasına geldiği gibi düzenleme manasına da gelmektedir. Bu anlamıla belli sınırların arasında bulunan ve bölgedeki alanları resmi bir şekilde düzenlemek için yapılmış bölümleme olarak da anlaşılabilir.

\section{Sixième Arrondissement}

Paris, uluslararası alanda başta kültür, turizm, ekonomi, siyaset ve ticaret bağlamında çok önemli bir merkezdir. Bir merkez olarak Paris, çok zengin bir geçmişe sahiptir. Nitekim incelendiğinde Paris tarihi, M.Ö. 259 yılına kadar uzandığı görülmektedir. İlk yerleşim Seine kıyılarına Keltli bir kabile olan Parisiiler ile olmuştur. M.Ö. 52'de balıkçı köyü Romalılar tarafından fethedilmiştir ve Lutetia adında bir Gallo-Roma kasabası kurulmuştur. Şehir, dördüncü yüzyılda adını Paris olarak değiştirilmiş ve günümüzdeki adını almaştır. Bu dönemde, şehir Attila Hun ordusu saldırılarına maruz kalmıştır. Efsaneye göre, Paris sakinleri Saint Geneviève'nin (kentin koruyucu azizi) göstermiş olduğu müdahaleyle saldırılara karşı koyabilmiştir. 508'de Frankların ilk kralı Clovis I Paris'i imparatorluğunun başkenti yapmıştır. On birinci yüzyılda Paris, gümüş ticareti ile ve hacılar ve tüccarlar için stratejik bir yol olduğu için giderek daha ön plana çıkmış ve Avrupa'nın en önemli kentlerinden birine dönüşmüştür. (introducingparis, 2019; Hussey, 2007, s.13)

Şehir her zaman bugün olduğu kadar turistik ve cazibesi yüksek bir yer olmamıştır. 1850'lerde, kent bugünkü haline dönüşmesi adına çalışmalar başlatılmış ve sorunlara köklü çözümler bulunmaya çalışılmıştır. Şehrin bu dönüşümden geçmesinin ana nedenlerinden biri, mevcut ortaçağ havasının sokakları kirli, karanlık ve sağlıksız bir yer haline getirmesiydi (Copeland, 2019, s.1). O dönemki halinden çok fazla değişikliğe uğramadan günümüze kadar gelen Paris 75 numaralı ildir. Alan olarak 105 kilometre kare ile en küçük il olmasına rağmen kilometreye düşen insan sayısı bakımında 21234 ile en yoğun ildir (thelocal, 2019). Paris nüfusu 
1999 nüfus sayımında 2125246, 2006 sayımında ise 2181371 kişi olarak tespit edilmiştir. Sixième Arrondissement ise Paris ili içerisinde nüfus bak1mından 45332 nüfus ile 15inci sıradadır ve sadece 2 kilometre karelik bir alanı kapsamaktadır (map-france, 2019).

5. ve 7. ilçeler arasında, Paris'in Sixième Arrondissement, Seine Nehri'nin sol yakasında yer almaktadır (Julien, 1995, s.402-403; frenchmoments, 2019) bu bağlamda bölge sol yaka ismi ile de bilinmektedir. Latin Mahallesi'nin yanında bulunan Paris'in Sixième Arrondissement'i üç ana bölgeye ayrılmıştır: Saint-Germain- Prés, Lüksemburg ve Rue de Rennes'in güneybatı kesimi (europeupclose, 2019). Kentin en hareketli bölgelerinden biri olan 6. bölge. 20. yüzyılda birçok sanatçı ve yazara ev sahipliği yapmıştır. Nitekim Académie Française gibi bazı ünlü kurumlara ev sahipliği yapmaktadır. Sixième Arrondissement kültürel bir merkezdir ve Parisli yaşamın özünü temsil etmektedir. Bugün, sosyal sermayenin önemli bir bölümünü yani Paris'i benzersiz kılan şeylerin birçoğu bu bölge ve civarında bulunmaktadır (parisattitude, 2019).

Genel itibariyle bakıldığında Sixième Arrondissement ve özellikle Saint-Germain-des-Prés bölgesi, görkemli mimariyi, heybetli/sanat eseri ve eski evleri, yemyeşil terasları ve pitoresk (göz alıc1) Lüksemburg bahçesini birleştiren Paris'in zarafeti ve rafine edilmişliğin kalbini temsil etmektedir (wikivoyage, 2019). Bu çerçevede turistik olarak Eyfel Kulesini içinde barındıran le septième arrondissement yani yedinci bölgeden bir nebzede az popüler olsa da hala Paris'in en çok ziyaret edilen yerlerinde biri olma özelliğini taşımaktadır.

\section{Altıncı Daire-i Belediye-Sixième Arrondissement Karşılaştırması}

Altıncı Daire-i Belediye modern belediyecilik anlayışının ilk başladığı yer olarak ön plana çıkmasının yanında o bölgenin Levantenlerin çoğunlukta olduğu bir bölge olması açısından önem arz etmektedir. Bu durum ele alındığında sadece Levantenlerin değil aynı zamanda yurtdışı tecrübesi olan veya yüzünü batıya çevirmiş Osmanlı tebaasının da bölgeye rağbet göstermesi de bölgeyi diğerlerine nazaran bir adım öne çıkartmaktadır. Aynı şekilde Sixième Arrondissement de Paris'in en önemli kültür ve sa- 
nat merkezi olarak göze çarpmaktadır. Bunun yanında Seine (Sen) nehrinin kıyısında olması durumu da Altıncı Daire-i Belediye ile olan benzer bir ortak noktalarından biridir.

Günümüzde İstanbul'un bir megapol olmasına rağmen başkent olma özelliğini kurulduğun andan itibaren belki sadece son 90 küsur yıldır sürdürememesi durumu iki bölge arasındaki temel farklılıklardan biri olarak göze çarpmaktadır. Zira Paris halen Fransa'nın başkenti ve diğer birçok açından da merkezi olma konumunu devam ettirmektedir. Ancak iki bölgenin de etraflarındaki bölgelerle beraber ülkenin en önemli cazibe merkezi olmaları durumu hala devam etmektedir. İlk aşamada İstanbul'un ticaret merkezi olarak dikkat çeken Altıncı Daire-i Belediye bölgesi günümüzde Sixième Arrondissement daha çok benzeyerek daha çok kültürel ve sosyal yönleri ile ön plana çıkmaktadır.

\section{Sonuç ve Değerlendirme}

Fransa özellikle de Paris dünyadaki aydınlanma hareketlerine ilham kaynağı olduğu için birçok ülkenin aydınının bu kentten bir şekilde geçtiği ve hatta oradan belli izler taşıdı̆̆ııı görmek mümkündür. Nitekim Fransız olmayan hem sağ hem sol düşüncenin öncülerinin birçok fikrinin öncülerinin Paris'te özellikle de çalışmanın konusunu oluşturan Sixième Arrondissement' de bulundukları görülmektedir.

Bu bulunmaları fikri alt yapılarını şekillendirmeleri bağlamında Fransız entellekütüel ortamının sunduğu avantajların yanında Paris'in de katk1sı büyüktür (Birnbaum, 1971, s.204). Bu bağlamda değerlendirildiğinde Türk modernleşmesi süreci de aynı temellere sahiptir. Tanzimat'tan Cumhuriyet'e gelinen zaman zarfındaki Türk kamu yönetiminin yeniden yapılanmasının ana faktörü imparatorluğun mevcut olan geleneksel yapısını dönüştürecek Batılı fikir ve düşüncelerden esinlenen modernleşme süreci simgelemektedir. O dönem itibariyle batının fikri manada merkezi konumundaki Fransa bu konuda örnek olması gayet normal bir süreçtir. Osmanlı Devleti modernleşme sürecinin başlaması ile ilk defa bu dönemde içine kapanık bir siyasal sistem olma niteliğini bir kenara bırakarak yüzünü batıya dönmüştür. Bu çerçevede özellikle Batıda açılan büyükelçilikler ve eğitim için gönderilen öğrencilerin de etkisiyle dışa açık, Batılı 
ülkelerle etkileşim halinde olan, yönetsel ve toplumsal değerlerini Batı eksenli bir şekilde yeniden düzenleye çalışan bir durumda kamu yönetimini daha iyi ve başarılı hale getirmeyi hedeflemiştir. Fakat söz konusu modernleşme, batılı kurumların Osmanlı toplumunun geleneksel yapısı göz ardı edilerek jakobenci bir mantık ile uygulanması nedeniyle, içerik ve mantık açısından sonuç verememiştir (Demirel, 2011, s.107).

Çalışmanın ana eksenini oluşturan karşılaştırma da ise göründüğü üzere iki bölgenin de birbirine birçok noktası ile çok benzediğini söylemek mümkündür. Ancak iki bölgenin tarihsel süreç içerisindeki yaşmış oldukları değişimler bağlamında değerlendirildiğinde Galata bölgesi daha kaotik ve karmaşık bir halde iken Paris'teki karşılığının bundan uzak daha rafine ve sakin bir yer olduğu söylenebilir. Bunu söylerken Paris'in dünyanın en çok turist çeken şehirlerinden biri olduğu göz ardı edilmemiştir. Söz konusu kanıyı güçlendiren en önemli veri ise Paris'in ve etrafının nüfusunun 5 milyon civarı iken İstanbul ve civarının yanı metropoliten alanın neredeyse 20 milyon olması gösterilebilir.

Sonuç olarak Türk yerel yönetim modernleşmesine örnek olması hasebiyle Sixième Arrondissement' in ismi ve cismi ile örnek alınması tabiri caizse absürt bir durum oluşturmaktadır. Bu durum başarılı örnekler olsa dahi Türk kamu yönetiminin modernleşmesinin içinde bulunduğu durumun anlaşılması açısından önem arz etmektedir. 


\title{
EXTENDED ABSTRACT
}

\section{Comparison of The Sixième Arrondisse and Sixth Region in Turkey Which is First Modern Experience of Local Government in Turkey *}

\author{
Abdullah Aydın \\ Mustafa Kemal University
}

The need for local governments to emerge as a result of the crowding of cities is a necessity for the Western world. As a result of the rapid migration from the village to the city, the population balance between the village and the city has deteriorated considerably and the cities have started to become uninhabitable. One of the biggest factors that made the cities uninhabitable was the chaos of service at the point of who would do the urban services. The West, who has tried to find long-term workarounds to this problem, decided that it was insufficient to produce services with workarounds and decided to establish a local government. It is clear that this is not only a process related to the process but also the bourgeois favor of the bourgeois-Aristocratic struggle. The Aristocracy argued that the bourgeoisie's demands on local services had to be ignored or should be overcome. The bourgeoisie emphasized the need to provide urban services to individuals and businesses, at least to a minimum, by the state. In the final analysis, the bourgeoisie won and the local governments started to become institutionalized in the modern sense.

The process is similar but not as the historical development of local governments in Turkey has followed almost parallel processes. More precisely, developments in the West, especially in France, have been followed by an Ottoman local government model. One of the biggest indicators of this is the Altıncı Daire. The name of the Altıncı Daire (Sixth Region), which was established in the area covering Beyoğlu and Galata regions, was inspired by Sixieme Arrondissment (Sixth District), where the most prominent and modern sections of Paris where prominent Ottoman bureaucrats were sent for educational purposes and lived for some time during the Tanzimat period (Eryılmaz 2005, s.393). 
In this study, it is tried to reveal the similarities between Sixieme Arrondissment in Paris and the Altıncı Daire established in Beyoğlu and Galata regions by focusing on the Ottoman reflections of French local government regulations. In doing so, it will be mentioned in Turkish and French local governments, but this narration will not be in the form of a detailed and chronological narrative. Because the subject matter mentioned in the literature is one of the main issues. Instead of working constitutes the main perspective Altınci Daire associated with Sixieme Arrondissment in Paris reasons mentioned and in a number of important breaking point in a region in France, in what way Turkey has emphasized that an example to local government tradition.

The Altınc Daire is the first place in which the concept of modern municipalism is first started and it is important because it is a region in which the region has the majority of Levantines. Considering this situation, not only the Levantines but also the Ottoman subjects, who have experience abroad or who turned their faces to the west, make the region one step further than the others. Similarly, the Sixième Arrondissement stands out as the most important cultural and artistic center of Paris. Besides, the fact that it is on the banks of the Seine (Sen) river is one of the similar points with the Altınc1 Daire.

Although Istanbul is a megapolis, the fact that the capital cannot be maintained for only the last 90 years since it was established is one of the main differences between the two regions. Paris is still the capital of France and is still the center of many other aspects. However, it is still the case that the two regions are the most important attractions of the country with the surrounding regions. In the first phase, the Altınc1 Daire of Istanbul, which stands out as the commercial center of Istanbul, is now more similar to the Sixième Arrondissement and is more prominent with its cultural and social aspects.

Since France is a source of inspiration for enlightenment movements in the world, especially in Paris, it is possible to see that the intellectuals of many countries have passed through this city and even have certain traces. Indeed, the pioneers of many ideas of the pioneers of both non-French and right-wing thinkers were found in Paris, particularly in the Sixième Arrondissement, the subject of the study. 
In addition to the advantages offered by the French intellectual environment in the context of shaping the idea infrastructures of these finds, Paris has also contributed a great deal (Birnbaum, 1971: 204). In this context, the Turkish modernization process has the same foundations. The main factor in the restructuring of the Turkish public administration from the time of the Republic of Tanzimat to the Republic symbolizes the modernization process inspired by Western ideas and ideas that will transform the existing traditional structure of the Empire. At that time, France, which was the center of the West in the sense of the idea, is a very normal process. When the Ottoman State began its modernization process, it turned to the west for the first time, leaving aside an inherent political system in this period. In this context, it aimed to make public administration better and more successful in a situation that is open to the West with the effect of the embassies and students sent for education, and interacting with the Western countries and re-organizing their managerial and social values in a Western axis. However, this modernization did not give any results in terms of content and logic due to the fact that Western institutions were implemented with logic by ignoring the traditional structure of Ottoman society (Demirel, 2011: 107).

The comparison of the main axis of the study, as it is seen, is very similar to the two regions. However, when the two regions are considered to be more chaotic and complex in the context of the changes they have experienced in the historical process, it can be said that the equivalent in Paris is a more refined and quiet place. In saying this, Paris was one of the most touristy cities in the world. The most important data reinforcing this argument is that the population of Paris and its surroundings are around 5 million, while the metropolitan area, as well as Istanbul and its surroundings, is almost 20 million.

As a result, the example of the modernization of the Turkish local government, the name of the Sixième Arrondissement and the object is taken as an example of the absurd situation. This is important in terms of understanding the situation in which the modernization of Turkish public administration even if there are successful examples. 


\section{Kaynakça / References}

Aktepe, M. (1982). Dünkü Fransızlar Blak Bey ve oğlu M. Alexandre Blaeque ve Edouard Blaeque. Tarih Dergisi, 33, 255-270.

Belli, A. (2017). Türk yerel yönetim sisteminin yerellik ilkesi açısından değerlendirilmesi. TURKISH STUDIES -International Periodical for the Languages, Literature and History of Turkish or Turkic, (Prof. Dr. Tahsin Aktaş Armağanı) 12(3), 75-92.

Bayram, P. (2017). 19. Yüzyıl Osmanlı Devleti'nde kentleşme: Yönetsel reformlar ile Osmanlı aydınlarının kent üzerine izlenimlerine dayalı karşılaştırmalı bir inceleme. Laü Sosyal Bilimler Dergisi, 8(2), 227244.

Bozkurt, N. (2007). İbrahim Hakkı (Paşa)' nın 1877 tarihli dersa'âdet belediye kanunu'na dair lâyihası. Dumlupinar Üniversitesi Sosyal Bilimler Dergisi, 18, 21-40.

Birnbaum, N. (1971). Toward a critical sociology. New York:Oxford University Press.

Canatan, B. (2001). Fransa'da yerinden yönetimin anayasal kaynakları. Çağdaş Yerel Yönetimler Dergisi, 10(1), 7-25.

Copeland T., Paris (2019) , France The City of Light, http://depts.washington.edu/open2100/Resources/1_OpenSpaceSystems/Open_Space_Systems/paris.pdf, (Erişim Tarihi: 11.01.2019).

Çiçek, Y.(2014). Geçmişten günümüze Türkiye'de yerel yönetimler. KSÜ Sosyal Bilimler Dergisi, 11(1), 53-64.

Daemen H. ve Schaap L. (2000). Development in Local Democracies, Citizen and city. Ed. Daemen H. ve Schaap L., Developments in fifteen local democracies in Europe içinde (s.129-144), Delft, Eburon.

Demirel, D. (2011). Tanzimat'tan Cumhuriyet'e kamu yönetiminde yeniden yapılanma (1839 - 1923). Türk İdare Dergisi, 473, 97-111.

Erbay, Y.(1999). Fransa'da idari sistem ve yerel yönetimler. Çağdaş Yerel Yönetimler Dergisi, 8(2), 58-74.

Ergin, O. N. (1934). Beledi bilgiler. İstanbul: İstanbul Matbaacılık ve Neşriyat T.A.Ş. yayınları.

Eryılmaz, B. (2002). Belediyelerde demokrasi geleneği ve değişim ihtiyacı. Çağdaş Yerel Yönetimler, 11(3), 6-21. 
Gözler K. (2019). Türk belediye sistemi üzerinde Fransız etkisi: 3 Nisan 1930 tarihli belediye kanunu Fransa'dan mı iktibas edilmiştir?. Çă̆daş Yerel Yönetimler Dergisi, 28 (1-2), 1-24.

http://beyoglu.bel.tr/belediye-tarihcesi-3.html, (Erişim Tarihi: 14.01.2019). https://islamansiklopedisi.org.tr/evkaf-i-humayun-nezareti, (Erişim Tarihi: 14.01.2019).

http://www.mimdap.org/?p=2372, (Erişim Tarihi: 11.01.2019).

http://www.tas-istanbul.com/pera/pera-sefaretleri/, (Erişim Tarihi: 14.01.2019).

http://www.tdk.gov.tr/index.php?option=com_bts\&arama=ke-

lime\&guid=TDK.GTS.5c9e81864200e7.84558158, (Erişim Tarihi: 15.01.2019).

https://www.introducingparis.com/history, Erişim Tarihi: (17.01.2019). https://www.thelocal.fr/20160830/everything-you-need-to-know-aboutfrances-dpartements, (Erişim Tarihi: 18.01.2019).

http://www.map-france.com/Paris\%206e\%20Arrondissement-75006/, (Erişim Tarihi: 19.01.2019).

https://fr.wikivoyage.org/wiki/6e_arrondissement_de_Paris, (Erişim Tarihi: 12.01.2019).

https://vivreparis.fr/6e-arrondissement-de-paris-pourquoi-on-laime/, (Erişim Tarihi: 12.01.2019).

https://europeupclose.com/article/paris-6th-arrondissement/, (Erişim Tarihi: 01.01.2019).

https://infos.parisattitude.com/en/6th-arrondissement/, (Erişim Tarihi: 02.01.2019).

https://frenchmoments.eu/sixth-arrondissement-of-paris/, (Erişim Tarihi: 02.01.2019).

Hussey, A. (2007). Praise for Paris: The secret history. Usa:Bloomsbury

Julien P. (1995). French towns, Higher Urban Functions and Strategic Employment, 32 (2), 401-423.

Keleş, R. (2012). Yerinden yönetim ve siyaset. İstanbul:Cem Yayınevi,

Koçak, S. Y. ve Ekşi, A. (2010). Katılımcılık ve demokrasi perspektifinden Türkiye'de yerel yönetimler. SDÜ Fen Edebiyat Fakültesi Sosyal Bilimler Dergisi, 21, 295-307.

Ladrech, R. (1994). Europeanization of domestic politics and institutions: The case of France. Journal of Common Market Studies, 32(1), 69-88. 
Minister de 1'Interieur (2018). Les Collectivites Locales en Chiffres . Paris: Direction Generale des Collectivites Locales.

Ortaylı, İ. (1985). Tanzimat'tan cumhuriyet'e yerel yönetim geleneği (18401878). İstanbul:Hil Yayınevi.

Ökmen, M. ve Yılmaz, A. (2009). Klasik dönemden tanzimat'a Osmanlı kenti ve yerel yönetimler. Dumlupınar Üniversitesi Sosyal Bilimler Dergisi, 23, 91-112.

Özdemir, M. (2011). Türkiye'de turizmin Başlaması: Osmanlı' da sanayileşme çabaları: Sergi-i Umum-i Osmanî (1863 İstanbul uluslararası sergisi). Anatolia: Turizm Araştırmaları Dergisi, 22(1), 87-90.

Karayiğit, M. T. (2016). The EU and Local governments. Strategic Public Management Journal (SPMJ), 2(4), 1-20.

Kayıkçı, S. (2003). 1982 reform yasası sonrası Fransa' da yerel yönetimler ve yerel özerklik şartı. Çă̆daş Yerel Yönetimler Dergisi, 12(3), 22-47.

Kazgan, H. (2014). Osmanlı finansinda Galata bankerleri. İstanbul:Tarihçi Kitabevi Yayınları.

Keleş, R. (2010). Avrupa'ya uyum sağlama sürecinde Türkiye'de yerel yönetimler. (N.Falay, A.Kesik, M. Çak, M. Karakaş, Ed.). Türkiye'de Yerel Yönetimlerin Sorunları ve Geleceği içinde (s. 11-26). Ankara: Seçkin Yayıncılık.

Pamuk, Ş. (1993). Osmanlı-Türkiye iktisadi tarihi. İstanbul: Gerçek Yayınevi. Seyitdanlığlu, M. (1995). Bir belge yerel yönetim metinleri (I). Çă̆daş Yerel Yönetimler, 4(6), 85-102.

Reigner, H. (1999). The transformations of local government in France: Towards a co-administration model between local authorities and state field services, ECPR Joint sessions of workshops, Workshop 1: Politicians, Bureaucrats and Institutional Reform, Mannheim 26-31 March 1999.

Şengül, R. (2012). Fransa'da yerinden yönetim politikalarının belediye yönetimine etkileri. Mustafa Kemal Üniversitesi Sosyal Bilimler Enstitüsü Dergisi, 9(20), 31-44.

Tan, M. ve Belli, A. (2013). Yerel kalkınma, yerel demokrasi ve katılım: Kahramanmaraş ölçeği. (M., Ökmen, U. Çağatay, ve B.A. Görmez, Ed.). Küreselleşme-Yerelleşme Dikotomisinde Yerel ve Bölgesel Kalkınma-Kamu Yönetimi Perspektifi içinde (s.251-283). Ankara: Orion Kitabevi. 
Taş, E. ve Çiçek, Y. (2017). Türkiye'de kent konseylerinin bilinirliği/tan1nurlığı: GAP bölgesi örneği. Sobider Sosyal Bilimler Dergisi, 16,305332.

Tekeli, İ. (1985). Tanzimat'tan cumhuriyet'e kentsel dönüşüm. Tanzimattan Cumhuriyete Türkiye Ansiklopedisi, 3, 878-890.

TESEV. (2009). Yerel yönetim sistemleri Türkiye ve Fransa, İspanya, İtalya, Polonya, Çek Cumhuriyeti. İstanbul: TESEV Yayınları,

Toprak, Z. (1993). Altıncı Daire-i Belediye. Dünden Bugüne İstanbul Ansiklopedisi, 1, 220-223.

Ünal, F. (2011). Tanzimat'tan cumhuriyete Türkiye'de yerel yönetimlerin yasal ve yapısal dönüşümü. Sosyal Bilimler Dergisi, 30, 241- 248.

Wollmann, H. (2008). Reforming local leadership and local democracy: The Cases of England, Sweden, Germany and France in Comparative Perspective. Local Government Studies, 34, 2, 279 - 298.

\section{Kaynakça Bilgisi / Citation Information}

Aydın, A. (2019). Türkiye'de ilk modern yerel yönetim denemesi olan altıncı daire-i belediye ile sixième arrondissement karşılaştırması. OPUS-Uluslararası Toplum Araştırmaları Dergisi, 11(18), 2708-2727. DOI: 10.26466/opus.561163 